[4] S. Schmit-Nielsen. Die Beziehung des Molkeneiweisses zùr Labgerinnung (Parakaseinbildung). Beiträg z. Chem. Pysiol. ù. Pathol. 1907, 9, 322.

[5] N. C. Wright. The action of Rennet and of Heat on Milk. Bioch. Journ., $1924,18,245$.

[6] A. W. Bosworth. The action of Kennin on Casein. Journ. of Biol. Chem. $1913,14,203-236$.

Composition and proferties of same Caséin and Paracasein compounds. NewYork State Agricultural Experiment Station Technical, Bulletin, no 26, 1912.

[7] A. HaRden et A. Macallum. Bioch. Journ, 1914, 8, 90.

[8] L. S. Palmer et G. A. Richardson. The eolloid chemistry of Rennet Coa. gulation. Journ. Series Paper 548 Minnesota agric. Exp. Stat.

[9] Ch. Porcher. Loc. cit., p. 430.

[10] Ch. Poroher. Loc. cit., p. 449.

[11] Ch. Porcher. Loc. cit., p. 421.

[12] J. L. Soret. Recherches sur l'absorption (5e Mémoire). Arch. de Sc. phys. et natur. (33 ${ }^{\mathrm{e}}$ période), $\mathrm{X}, 429-495,1883$.

A. Wynter Buyth. The ultra-violet absorption spectrum of proteids in relation to tyrosine. Journ. of the Chem. Soc., LXXXV (Transactions), 1162-1899.

DHere. Recherches spectrographiques sur l'absorption des rayons ultraviolets par les albumines, les protéides et leurs dérivés. Fribourg, 1909.

Gladys A. Ansuow et Mary Louise Foster. The influence of substituent groups on the visible and ultra-violet absorption spectra of amino acids and related substances. J. Biol. Chem., 97, p. 37-46, 1932.

Frank CAMpBel. SмттH. The ultra-violet absorption spectra of certain aromatic amino acids and of the serum proteins. Proc. Roy. Soc., 104, 1929, p. 198.

[13] F. Vhìs et Prager. Sur la structure spectrale ultra-violette de certaines substances protéiques. Arch. Phys. Biol., X, 1932, p. 5.

\title{
RECHERCHES SUR LES PRÉSURES NATURELLES ET LES CULTURES EMPLOYÉES EN FROMAGERIE
}

\author{
par le Dr.W. DORNER
}

Bactériologiste à l'Etablissement fédéral d'Industrie laitière (Liebefeld-Berne).

Depuis l'année 1875 où le savant allemand CoHN affirmait que la maturation des fromages était produite par des bactéries et que ces bactéries provenaient de la présure, bien des progrès ont été effectués. Dans l'ensemble, les idées de СоHN ont été confirmées par les travaux de nombreux savants, en particulier de FreUdenReIch, Duclaux et Thönr. C'est ce dernier qui a mis en évidence le rôle des bâtonnets acidolactiques dans la présure et a proposé leur emploi en cultures pures. Plus tard, des observations de PETER et les travaux de KüRsteiner ont établi, qu'à côté des lactobacilles, les streptocoques jouaient un rôle important dans les présures. 
Entre temps, OrLa-Jensen, qui a été un des pionniers dans la question de la maturation du fromage d'Emmenthal, faisait une étude serrée des bactéries lactiques et proposait une nouvelle classification pour celles-ci. Il découle de ses travaux qu'il existe un plus grand nombre d'espèces de bactéries lactiques qu'on ne l'admettait auparavant. Dans un travail en collaboration avec M. KARNIOKI, et qui sera publié dans l'Annuaire agricole de la Suisse, nous avons examiné les genres de présures et de cultures, les plus usités en Suisse, quant à leur flore microbienne en tenant particulièrement compte des travaux récents sur la classification. Il résulte de ces recherches que les bactéries lactiques les plus fréquentes dans les présures naturelles et les cultures au petit-lait ne sont pas comme on l'admettait jusqu'ici le Bact. casei $\Sigma$ ou, comme on le nomme maintenant, le Thermobacterium helveticum et le Streptococcus lactis, mais bien le Thermobacterium lactis et le Streptococcus thermophilus.

Le Thermobacterium (en abrégé : $T b m$.) lactis était prépondérant ou en très grand nombre dans $85 \%$ des échantillons de présure ou de cultures analysés tandis que ses proches parents le $T b m$.helveticum et le Tbm. bulgaricum n'ont été trouvés respectivement que dans 26 et $11 \%$ des échantillons. La culture de fromagerie contient le Tbm. helveticum.

Dans $88 \%$ des cas où des streptocoques ont pu être isolés, il s'agissait de Streptococcus (en abrégé : Str.) thermophilus et dans $27 \%$ des cas seulement de Str. lactis. Toutes les sortes de présures et de cultures examinées présentaient cette prépondérance de $T b m$. lactis et de Str. thermophilus. La culture de fromagerie ( $T b m$. helveticum) et le yoghourt ( $\mathrm{Tbm}$. bulgaricum et Str. thermophilus) font exception. Même la culture au petit-lait ensemencée de $4 \%$ de culture de fromagerie eontenait le $\mathrm{Tbm}$. lactis en prépondérance dans $60 \%$ des cas.

La seule différence notable qui existait entre les présures (macérations de caillettes de veau) et les cultures en petit-lait réside dans le fait que des bétabactéries ont été décelées dans plus de $85 \%$ des présures examinées tandis qu'elles n'ont été trouvées que dans $12,5 \%$ des eultures au petit-lait. Les recherches ont porté sur des présures à la recuite et au petit-lait ainsi que sur du petit-lait mûri avec ou sans addition de culture de fromagerie. Un certain nombre d'échantillons de cultures de fromagerie et de yoghourt ont également été examinés.

Des recherches récentes ont mis en évidence un autre point relatif aux cultures et présures à savoir : le pouvoir acidifiant. L'effet d'inhibition qu'ont les ferments lactiques sur les microbes du gonflement en particulier dépend de leur faculté de produire rapi- 
dement de l'acide lactique. D'autre part, l'effet d'une présure ou culture dans le fromage est également dépendant de la rapidité avec laquelle l'acidification s'amorce sous presse. Nous avons cherché un moyen de mesurer le pouvoir acidifiant des présures et cultures et nous avons finalement adopté l'index suivant comme mesure empirique de la vitesse avec laquelle les bactéries peuvent acidifier le fromage : $10 \mathrm{~cm}^{3}$ exactement de lait stérilisé ou bouilli depuis peu sont additionnés de $1 \%$, soit $0,01 \mathrm{~cm}^{3}$ de présure ou de culture, réchauffés à $38^{\circ} \mathrm{C}$, puis placés au thermostat à cette même température pendant exactement 5 heures. A ce moment on détermine l'augmentation du degré d'acidité comparativement à du lait témoin non ensemencé.

Les facteurs les plus importants qui ont une influence sur le pouvoir acidifiant ou la virulence de la présure ou culture sont les: suivants :

\section{a) Nature de la flore microbienne.}

Les différentes espèces de ferments lactiques ont la propriété d'acidifier plus ou moins rapidement le lait. C'est ainsi, qu'en règle générale, $\mathrm{Tbm}$. lactis acidifie plus rapidement que $\mathrm{Tbm}$. helveticum et en particulier que la souche de Tbm. helveticum contenue dans la culture de fromagerie. Cette dernière est sans doute une des cultures les moins virulentes qui soient. De même le Str. thermophilus travaille plus rapidement que le Str. lactis qui a de la peine à se développer au-dessus de $42^{\circ} \mathrm{C}$. Le Str. thermophilus travaille également plus vite que les ferments lactiques en forme de bâtonnets à la température de jeune fromage $\left(46-48^{\circ} \mathrm{C}\right.$.).

La conséquence de ce qui précède est qu'une présure contenant beaucoup de streptocoques thermophiles doit acidifier plus rapidement qu'une présure qui n'en contient pas. Nous avions pu confirmer ce fait, mais nous avons observé également qu'une culture pure de streptocoques n'est pas en mesure d'acidifier aussi rapidement qu'un mélange de thermobactéries (bâtonnets) et de streptocoques. Il semble qu'il existe entre ces deux genres de bactéries une sorte de symbiose qui fait que les mélanges des deux présentent une activité supérieure à celle des composants pris isolément.

b) Influence du liquide qui sert à la préparation des présures.

La nature du liquide qui sert à préparer la culture ou la présure a une influence considérable sur le pouvoir acidifiant. Il semble que plus ce liquide est riche en matières azotées, plus le pouvoir acidifiant de la culture est élevé. Il se pourrait aussi que le potentiel d'oxydo-réduction joue un rôle dans eette question. La eulture mixte en lait peut avoir un pouvoir acidifiant 10 fois plus élevé qu'une 
présure présentant à peu près la même flore microbienne. Les cultures en petit-lait de leur côté sont plus virulentes que les cultures sur recuite.

c) Influence de l'acidité des cultures ou présures.

On sait que les ferments lactiques finissent par périr sous l'influence de l'acide lactique qu'ils produisent. Avant de périr ils s'affaiblissent. L'expérience du laboratoire a démontré qu'à partir de 35 à $40^{\circ}$ d'acidité le pouvoir acidifiant des cultures diminuait progressivement à mesure que l'acidité augmentait. Les cultures les plus virulentes sont celles qui ont une acidité de 25 à $35^{\circ}$ SohxletHenkel au bout de 24 à 36 heures.

d) Influence de l'âge des cultures.

L'âge des cultures a sur leur pouvoir acidifiant un effet analogue à celui de l'acidité. La virulence des cultures augmente jusqu'à un certain moment et décroît ensuite avec l'âge. En général des cultures de 24 à 36 heures sont les plus actives.

Cet exposé des facteurs qui modifient la virulence ou le pouvoir acidifiant des présures ou cultures permettra peut-être au fromager de mieux adapter sa présure au lait de chaudière dont il dispose.

\title{
QUELQUES CONCLUSIONS PRATIQUES TIRÉES DE HUIT ANS D'ÉTUDE DE LA IMAMMITE EN EUROPE ET EN AMÉRIQUE DU NORD
}

par

\author{
J. M. ROSELL \\ Docteur en Médecine,
}

Chef du Département de Bactériologie,

Institut Agricole de l'Université de Montréal, Oka, Québec.

Bactériologiste, Ecole provinciale de Laiterie, Québec.

(Fin.)

\begin{abstract}
Valeur comparative au point de vue du diagnostic de chacun de ces tests chimiques et biologiques pour le diagnostic de la mammite. - De nombreuses et copieuses études ont été publiées sur ce sujet pendant les dix dernières années. Les résultats d'études complètes ont été publiés, en dehors de nombreuses autres publications, dans les ouvrages de BREED, BAKER, KLIMMER, Seelemann, Gloy, Bischoff, Rooder, Hucker, Miller et RoselL. Nous allons maintenant résumer les idées qui nous paraissent les plus acceptables après avoir étudié la question pendant près de huit ans.
\end{abstract}

